\title{
Ten strategies to optimize early mobilization and rehabilitation in intensive care
}

\author{
Carol L. Hodgson ${ }^{1,2^{*}} \mathbb{0}$, Stefan J. Schaller ${ }^{3,4,5}$, Peter Nydahl ${ }^{6}$, Karina Tavares Timenetsky ${ }^{7}$ and Dale M. Needham ${ }^{8,9}$
}

\section{Introduction}

In the last decade, there have been more than 40 randomized trials evaluating early mobilization and rehabilitation in intensive care units (ICU) [1]. Such trials generally aim to reduce the incidence of ICU-acquired weakness (ICUAW) which is associated with poor longterm survival, physical functioning, and quality of life [2]. At least eight international guidelines have recommended ICU early mobilization and rehabilitation [3].

Despite supporting evidence and guidelines, implementation of ICU mobilization and rehabilitation is highly variable[4]. Hence, we report on 10 steps to help ICU clinicians in optimizing early mobilization and rehabilitation.

\section{Create multidisciplinary team with designated champions}

Early mobilization and rehabilitation is more successful in ICUs with a culture that prioritizes and values this intervention [5]. Mobility champions can help develop this culture using leadership and communication skills to educate, train, coordinate, and promote patient mobilization $[3,4,6]$. They support staff with an emphasis on safety and practical skills to improve the team's confidence and capabilities [6].

\footnotetext{
*Correspondence: carol.hodgson@monash.edu

${ }^{1}$ Australian and New Zealand Intensive Care Research Centre, School of Public Health and Preventive Medicine, Monash University, 3/553 St Kilda Rd, Melbourne, VIC 3004, Australia

Full list of author information is available at the end of the article
}

Use structured quality improvement (QI) processes A structured QI approach can greatly enhance successful implementation of early mobilization and rehabilitation [7]. One approach to QI includes four steps: (1) summarizing the evidence; (2) identifying barriers (e.g., sedation or lack of equipment); (3) establishing performance measures (e.g., sedation targets, frequency, and level of patient mobilization); and (4) ensuring all eligible patients receive the intervention (via appropriate engagement, education, execution, and evaluation) $[6,7]$.

\section{Identify barriers and facilitators}

A systematic review identified 28 unique barriers to early mobilization and rehabilitation, including patientrelated barriers (e.g., physiological instability and medical devices), structural barriers (e.g., limited staff and equipment), procedural barriers (e.g., lack of coordination and delayed screening for eligibility), and cultural barriers (e.g., prior staff experience and ICU priorities for patient care) [4]. There are many strategies to effectively overcome barriers, including implementation of safety guidelines; use of mobility protocols; interprofessional training, education, and rounds; and inclusion of physician champions [4].

\section{Promote multi-professional communication}

The multi-professional team effort required for early mobilization and rehabilitation program depends on optimal communication. We recommend that interprofessional communication is facilitated using a structure adapted to the individual ICU that allows (algorithmbased) mobilization goals, including an opportunity for all team members to raise concerns and ensure flow of original author(s) and the source, provide a link to the Creative Commons licence, and indicate if changes were made. The images or other third party material in this article are included in the article's Creative Commons licence, unless indicated otherwise in a credit line to the material. If material is not included in the article's Creative Commons licence and your intended use is not permitted by statutory regulation or exceeds the permitted use, you will need to obtain permission directly from the copyright holder. To view a copy of this licence, visit http://creativecommons.org/licenses/by/4.0/. The Creative Commons Public Domain Dedication waiver (http://creativeco mmons.org/publicdomain/zero/1.0/) applies to the data made available in this article, unless otherwise stated in a credit line to the data. 
information regarding mobility goals and achievement across staff and over time [8].

\section{Understand patient preferences}

ICU patients' experience with early mobilization and rehabilitation is variable. It may be tiring, uncomfortable and difficult, while at other times be motivating and rewarding for patients [9]. With improving cognitive status, patients may be shocked by the severity of their muscle weakness. In the early stages of critical illness, patients may prefer to focus on short-time goals (e.g., sitting in a chair) set by the multidisciplinary team [9]. As patients progress, they may become more engaged in goal setting and longer-term rehabilitation planning (e.g., walking longer distances, sitting outside) (Fig. 1).

\section{Adopt safety criteria}

Meta-analyses have demonstrated the safety of in-bed and out-of-bed ICU mobilization, with rare occurrence of serious events [10]. One method of assessing safety is a traffic light system that provides specific criteria, across respiratory, hemodynamic, neurological, and other body systems, to be considered in mobilizing individual patients [11]. In this system, "red light" criteria indicate an increased potential for a serious safety event during mobilization requiring experienced decision-making, "yellow light" indicates potential risk that should be evaluated in terms of benefits versus risks, and "green light" indicates that mobilization is generally safe [11].

\section{Implement care bundles for pain, sedation, delirium, and sleep}

Patients' sedation and delirium status is a common barrier to early mobilization and rehabilitation [4]. More broadly, pain, sedation, delirium, sleep, and early mobilization and rehabilitation are closely inter-related, as considered in clinical guidelines[3]. Assessment and management of these issues, via existing evidencebased practices (as synthesized in the guidelines), are important to maximize patients' ability to participate in rehabilitation.

\section{Obtain any necessary equipment}

Barriers to early mobilization and rehabilitation may include ICUAW, impaired physical functioning, traumatic injuries, and obesity [6]. Equipment can expand treatment options, increase patient mobility and activity levels, and reduce risk of injury to staff [12]. Selecting rehabilitation equipment may be challenging, with important considerations including the equipment cost/ availability, ability to share equipment between units or patients (including infection control considerations), and the physical space available for patient mobilization and for convenient storage of equipment. Evidence

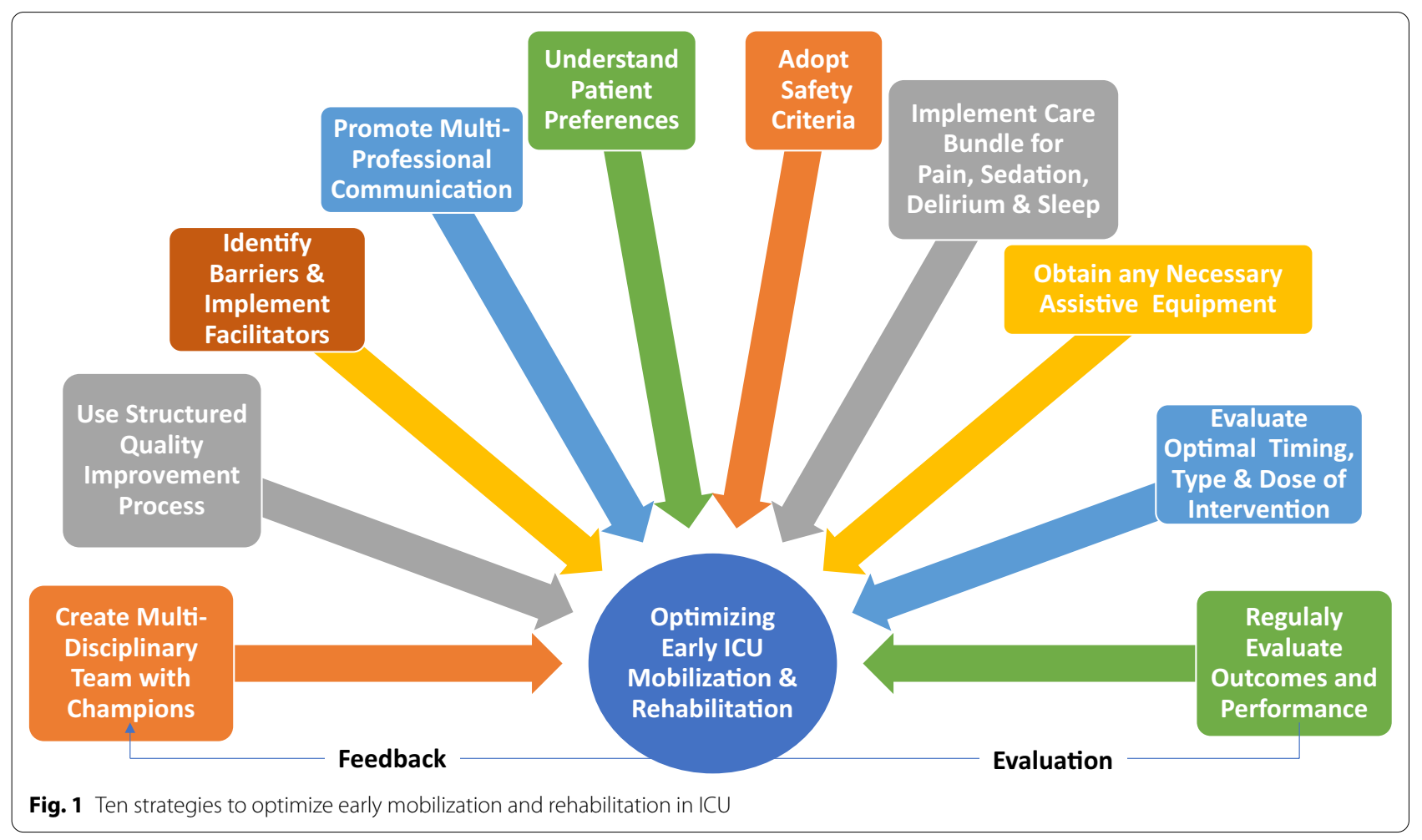


supporting use of specific equipment is still evolving, including evaluation of neuromuscular electrical stimulation (NMES), in-bed cycle ergometry, tilt tables, and other devices $[12,13]$.

\section{Evaluate optimal timing, type, and dose of intervention}

Important knowledge gaps exist regarding exercise, including the timing, type, and dose of interventions. There is some evidence suggesting that starting rehabilitation within 2 or 3 days of ICU admission may be superior to later initiation [3]. Types of interventions to be considered include active functional mobilization, inbed cycle ergometry, electrical muscle stimulation (with or without passive/active exercises), tilt tables, and use of various rehabilitation equipment. In addition, the intensity, duration, and frequency of each intervention type are important considerations [14]. Additional research is needed to further understand potential benefit or harm. Until that time, clinician judgement will play an important role and must be tailored to individual patients and to the dynamic nature of critical illness.

\section{Assess outcomes and performance}

Mobility and rehabilitation-related measures, appropriate to the ICU setting and integrated into clinical care, are needed to set patient goals and track their progress, allocate scarce rehabilitation resources to those patients who may benefit the most, and conduct evaluations of structured quality improvement programs [15]. Understanding patients' functioning prior to critical illness, and their own goals, are also important considerations.

\section{Conclusion}

Evidence is still evolving about early mobilization in ICU with ongoing large, multi-center trials. Further research is needed to understand the optimal timing, type and dose of interventions, and their effect on long-term patient outcomes. These 10 strategies provide guidance for implementing early mobilization and rehabilitation in the ICU with the goal of optimizing safety and effectiveness to improve patients' experiences and outcomes.

\section{Acknowledgements}

None.

\section{Authors' contributions}

CLH and DMN conceived the manuscript, all authors were involved in the preparation, editing, and final review of the manuscript.

\section{Funding}

Professor Carol Hodgson is supported by a National Health and Medical Research Council Investigator grant.

Availability of supporting data

Not applicable.

\section{Declarations}

Ethics approval and consent to participate

Not applicable.

\section{Consent for publication \\ Not applicable.}

\section{Conflict of interest}

$\mathrm{CH}$ is a principal investigator on a NHMRC-funded, multi-center Phase III randomized trial evaluating early mobilization in intensive care (GNT1120319).

DMN is a principal investigator on a $\mathrm{NIH}$-funded, multi-centered randomized trial (R01HL132887) evaluating nutrition and exercise in acute respiratory failure. This trial has received an unrestricted research grant and donated amino acid product from Baxter Healthcare Corporation and an equipment loan from Reck Medical Devices. DMN has previously provided consulting to Haisco-USA Pharmaceuticals, Novartis Pharma (Switzerland), and GlaxoSmithKline (UK). For all other authors, there is no conflicts of interest related to this manuscript.

\section{Author details}

${ }^{1}$ Australian and New Zealand Intensive Care Research Centre, School of Public Health and Preventive Medicine, Monash University, 3/553 St Kilda Rd, Melbourne, VIC 3004, Australia. ${ }^{2}$ Department of Intensive Care and Hyperbaric Medicine, The Alfred, Melbourne, VIC, Australia. ${ }^{3}$ Charité - Universitätsmedizin Berlin, corporate member of Freie Universität Berlin, Berlin, Germany. ${ }^{4}$ Department of Anesthesiology and Operative Intensive Care Medicine, Humboldt-Universität zu Berlin, Chariteplatz 1, Berlin, Germany. ${ }^{5}$ Department of Anesthesiology and Intensive Care, School of Medicine, Technical University of Munich, Munich, Germany. ${ }^{6}$ Nursing Research, Department of Anaesthesiology and Intensive Care Medicine, University Hospital of Schleswig-Holstein, Kiel, Germany. ${ }^{7}$ Department of Critical Care, Hospital Israelita Albert Einstein, São Paulo, SP, Brazil. ${ }^{8}$ Outcomes After Critical Illness and Surgery (OACIS) Group, Division of Pulmonary and Critical Care Medicine, Department of Physical Medicine and Rehabilitation, School of Medicine, Johns Hopkins University, Baltimore, MD, USA. ${ }^{9}$ School of Nursing, Johns Hopkins University, Baltimore, $M D$, USA.

Received: 19 August 2021 Accepted: 20 August 2021

Published online: 03 September 2021

\section{References}

1. Waldauf P, Jiroutkova K, Krajcova A, Puthucheary Z, Duska F. Effects of rehabilitation interventions on clinical outcomes in critically III patients: systematic review and meta-analysis of randomized controlled trials. Crit Care Med. 2020;48(7):1055-65.

2. Tipping CJ, Harrold M, Holland A, Romero L, Nisbet T, Hodgson CL. The effects of active mobilisation and rehabilitation in ICU on mortality and function: a systematic review. Intensive Care Med. 2017:43(2):171-83.

3. Lang JK, Paykel MS, Haines KJ, Hodgson CL. Clinical practice guidelines for early mobilization in the ICU: a systematic review. Crit Care Med. 2020;48(11):e1121-8.

4. Dubb R, Nydahl P, Hermes C, Schwabbauer N, Toonstra A, Parker AM, Kaltwasser A, Needham DM. Barriers and strategies for early mobilization of patients in intensive care units. Ann Am Thorac Soc. 2016;13(5):724-30.

5. Hodgson C, Bellomo R, Berney S, Bailey M, Buhr H, Denehy L, Harrold M, Higgins A, Presneill J, Saxena M, et al. Early mobilization and recovery in mechanically ventilated patients in the ICU: a bi-national, multi-centre, prospective cohort study. Crit Care (London, England). 2015;19:81.

6. Parry SM, Nydahl P, Needham DM. Implementing early physical rehabilitation and mobilisation in the ICU: institutional, clinician, and patient considerations. Intensive Care Med. 2018;44(4):470-3.

7. Needham DM, Korupolu R. Rehabilitation quality improvement in an intensive care unit setting: implementation of a quality improvement model. Top Stroke Rehabil. 2010;17(4):271-81.

8. Schaller SJ, Anstey M, Blobner M, Edrich T, Grabitz SD, Gradwohl-Matis I, Heim M, Houle T, Kurth T, Latronico N, et al. Early, goal-directed mobilisation in the surgical intensive care unit: a randomised controlled trial. Lancet. 2016;388(10052):1377-88. 
9. Corner EJ, Murray EJ, Brett SJ. Qualitative, grounded theory exploration of patients' experience of early mobilisation, rehabilitation and recovery after critical illness. BMJ Open. 2019;9(2):e026348.

10 Nydahl P, Sricharoenchai T, Chandra S, Kundt FS, Huang M, Fischill M, Needham DM. Safety of patient mobilization and rehabilitation in the intensive care unit. Systematic review with meta-analysis. Ann Am Thorac Soc. 2017;14(5):766-77.

11. Hodgson CL, Stiller K, Needham DM, Tipping CJ, Harrold M, Baldwin CE, Bradley S, Berney S, Caruana LR, Elliott D, et al. Expert consensus and recommendations on safety criteria for active mobilization of mechanically ventilated critically ill adults. Crit care (London, England). 2014;18(6):658

12. Darragh AR, Campo MA, Frost L, Miller M, Pentico M, Margulis H. Safepatient-handling equipment in therapy practice: implications for rehabilitation. Am J Occup Ther. 2013;67(1):45-53.

13. Zayed Y, Kheiri B, Barbarawi M, Chahine A, Rashdan L, Chintalapati S, Bachuwa G, Al-Sanouri I. Effects of neuromuscular electrical stimulation in critically ill patients: a systematic review and meta-analysis of randomised controlled trials. Aust Crit Care. 2020;33(2):203-10.

14. Paton M, Lane R, Paul E, Cuthburtson GA, Hodgson CL. Mobilization during critical illness: a higher level of mobilization improves health status at 6 months, a secondary analysis of a prospective cohort study. Crit Care Med. 2021;49(9):e860-9. https://doi.org/10.1097/CCM.0000000000 005058.

15. Parry SM, Remedios L, Denehy L, Knight LD, Beach L, Rollinson TC, Berney S, Puthucheary ZA, Morris P, Granger CL. What factors affect implementation of early rehabilitation into intensive care unit practice? A qualitative study with clinicians. J Crit Care. 2017;38:137-43.

\section{Publisher's Note}

Springer Nature remains neutral with regard to jurisdictional claims in published maps and institutional affiliations.
Ready to submit your research? Choose BMC and benefit from:

- fast, convenient online submission

- thorough peer review by experienced researchers in your field

- rapid publication on acceptance

- support for research data, including large and complex data types

- gold Open Access which fosters wider collaboration and increased citations

- maximum visibility for your research: over $100 \mathrm{M}$ website views per year

At BMC, research is always in progress.

Learn more biomedcentral.com/submissions 